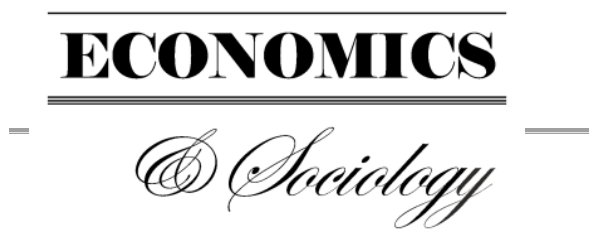

Yoon, D. (2018). Rising unemployment among young people and improved employment policy: The case of South Korea. Economics and Sociology, 11(4), 246264. doi:10.14254/2071-789X.2018/11-4/16

\author{
Donghun Yoon, \\ Korea Basic Science Institute, \\ Seoul, South Korea, \\ E-mail:ydh0@kbbsi.re.kr
}

Received: May, 2018

1st Revision: October, 2018

Accepted: November, 2018

DOI: $10.14254 / 2071-$

789X.2018/11-4/16

\section{RISING UNEMPLOYMENT AMONG YOUNG PEOPLE AND IMPROVED EMPLOYMENT POLICY: THE CASE OF SOUTH KOREA} JEL Classification: C83, J20,
J60, J64, J68.
ABSTRACT. Rising unemployment among the youth has become a major social issue for many nations globalwide. This paper would be discussing the rising unemployment among the youth in South Korea. Also, a policy proposal to increase the employment rate would be suggested. It is the objective of this paper to present the policy aiming to increase the employment rate and address the rising unemployment among the youth. In this paper, we surveyed 100 university students to study the effect of their career decisions and job search anxiety as they prepare for employment. The employment rate calculation is based on the data obtained from 'Higher Education in Korea' by the Minister of Education of South Korea. The result of the analysis show that job search anxiety had a positive effect on job-seeking activities. Also, career decisions did not have a positive effect on job-seeking activities. First, we discussed the problem of rising unemployment among the youth. Then, the causes of unemployment among the youth were analyzed through the examination of demand and supply at the labor market. The employment rate of university majors was analyzed to determine the employment trends among the youth in South Korea. The employment rate for Medical Science and Engineering majors was higher than the employment rate for Art, Physical Education, Humanities, and Education majors. This paper presents and discusses the solution to the rising unemployment among the youth through a policy proposal aimed at improving youth employment rate.

Keywords: unemployment among the youth, South Korea, policy, employment rate, human resource, job creation, demand, supply, job search anxiety, career decision.

\title{
Introduction
}

Recently, the unemployment rate in South Korea has increased due to the global economic slowdown. The gross domestic product (GDP) reduced from $3.3 \%$ (2014) to $3.3 \%$ (2016) in South Korea, while the unemployment increase from $3.5 \%$ (2014) to $3.7 \%$ (2016) (Ministry of Economy and Finance of South Korea, 2017). This has led to labor market polarization, an increase in the number of irregular employees as a result of structural changes 
at the labor market, and the employment capacity reduction in the economy. The rate of unemployment grew due to large-scale restructuring and changes in the modes of employment. Also, the latest of economic recessions has brought about long-term unemployment as a result of decreases in labor demand. It is also a serious social problem. Unemployment is a major concern in efficient utilization of social resources and is a personal issue for the many too. Unemployment causes serious social losses, such as; income cut-offs and other financial difficulties for the unemployed, the rising feelings of social injustice and potentially exacerbated conflicts, lower quality of human resources due to poorer technology skills and little knowledge, rising socioeconomic costs of the unemployment relief, etc. (Launov \& Wälde, 2016). All of the above together might lead to social unrest. The unemployed person is regarded as a lesser manpower in terms of labor competitiveness, income, and employment capacity. Furthermore, the unemployed person is classified as a protected person by the government at the national level (Falco \& Haywood, 2016). This also causes problems for the national economic base, such as extra social costs, higher inflation, etc. In South Korea, the middle class is consistently decreasing in numbers, while the lower income group has been increasing steadily. South Korean government has been looking out for solutions through policy changes that can spur job creation and improve the national employment rate. In this paper, we focus on the rising unemployment among the youth and offer our own solution to this serious social and economic problem.

\section{Literature review}

Job insecurity is defined as the anxiety experienced by people who are preparing for employment or who are proceeding with employment. It refers to the fear of employment failure, the fear of psychological pressure in the case of employment failure, and the fear of the threat posed by the factors considered to be barriers to employment (Schreurs et al., 2010). The existing research trend is on the job satisfaction and job stress in the workplace, and researchers are searching for policies that can improve the employment rate of young people, to arrest the rising unemployment of such demographic, by looking into all the issues discussed in this study. One of these issues is the job seeking stress, also known as the unemployment stress syndrome, which refers to the mental and physical pain that occurs as a result of one's repeated job failures or prolonged unemployment. Job stress can be defined as a state in which college students feel that their physical and psychological equilibrium is being destroyed by problems related to employment, which brings about a crisis, tension, and anxiety during college life. It can also be considered a form of stress that college students subjectively feel while preparing for their future employment. Job insecurity is a form of insecurity that can be defined as the insecurity of college students with regard to the prospect of obtaining future employment. Also, according to Spielberger's insecurity type, the insecurity that college students feel in an uncertain employment situation can be referred to as job insecurity. The college students in the upper grades feel relatively more anxious about their future employment than the college students in the lower grades. In general, job insecurity can be classified into the three categories discussed below (Reisel, et al., 2010). When college students experience job insecurity, they are irritable, uneasy, unconfident, and cannot concentrate on anything. Also, for their physical condition, their metabolism shows several sharp changes, and their heart is often pounding or they have difficulty breathing. At this time, as reported by the media or one's acquaintances, obtaining employment is difficult due to the recession, and many college students are experiencing job insecurity, especially those who are about to graduate, who are worried about their future employment. The college graduates who fail to get a job soon after they graduate also develop job insecurity. The causes of job insecurity can be classified into internal and external causes. The internal causes are the college major, transcript, level of foreign language ability, 
employment preparation, etc. The external causes, on the other hand, are the expectations of their families and friends, among others. Job insecurity refers to the feeling of insecurity felt by prospective college graduates and college graduates with during the employment preparation process. The right degree of job insecurity can serve as a positive motivation for employment preparation. On the other hand, excessive job insecurity due to employment uncertainty is bound to have a negative effect on employment preparation, and can make college students feel disappointment or develop depression, social phobia, or other similar conditions when extended over a long period.

Self-determination is the factor that determines the intrinsic motivation of individuals. It means that people's motivation level is determined by the degree to which individuals can control and adjust their own behavior or can guarantee their autonomy (Wininger, 2007). Motivation is usually classified into intrinsic motivation and extrinsic motivation. Intrinsic motivation refers to the source of the force that induces an individual's action, and often corresponds to the pleasure presented by a given task and/or the individual's interest in such task. Intrinsic motivation drives individuals to perform a certain task due to the pleasure presented by it and/or their interest in it. It also emphasizes the fact that the source of the force is within the individual. Extrinsic motivation, on the other hand, refers to an external stimulus (a reward, punishment, etc.) that makes an individual act. Intrinsic motivation and extrinsic motivation are discussed as research areas in the self-determination theory. Autonomy can include both intrinsic and extrinsic motivation; these two types of motivation are located on a continuous hierarchical line through the autonomy level. They can be classified into the five categories discussed below (Teixeira, 2012). Amotivation is a motivation type without selfdetermination. This situation pertains to the absence of the will to act. It lacks the efficacy for and regulation of the desired result cited in the self-determination theory. Individuals who suffer from it cannot control and adjust their own behavior. External regulation refers to the fact that an individual acts due to the reward promised for such action, the punishment to be imposed for non-action, etc. It is a heteronomous act without self-determination for compliance with a regulation or punishment evasion. The rationale for external regulation is "if an individual does not act, a problem will arise; as such, an individual is determined to act, according to the regulations, etc." Here, an individual acts to avoid guilt, anxiety, and criticism. Also, an individual acts to paint a good image of himself and to be recognized by others. In introjected regulation, there is no self-determination due to intrinsic motivation, only due to extrinsic motivation. The rationale for introjected regulation is "if an individual does not act, the others will not like him, and individuals want to obtain recognition by others." Here, an individual acts due to the sense of importance brought about by self-determination. Although in identified regulation an individual acts through self-determination, the individual acts for the attainment of his own goal rather than for the pleasure of doing so or due to the individual's interest in the task. Therefore, it is regarded as falling under extrinsic motivation. An individual who is intrinsically motivated acts due to the pleasure that he can obtain from doing so, due to his interest in the task, due to the satisfaction that he can derive from performing the task, etc. It represents the highest degree of autonomy. The rationale for intrinsic motivation is "an individual is interested and seeks pleasure, etc." The self-determination theory states that autonomy, competence, and relatedness are needed to promote intrinsic motivation as well as creative behavior, positive emotions, confidence, cognitive processing, satisfaction, etc. Autonomy refers to an individual's power to act based on his/her own values and interests, regardless of external influences. Competence refers to an individual's feeling of being capable as he continually interacts with his social environment thanks to the training opportunities for ability and competency development and the opportunities to express such abilities and competencies that have been presented to him. Individuals continually seek to promote/maintain and apply their own abilities and competencies in optimal situations, and 
competence pertains more to one's confidence in his abilities and competencies rather than to the training that one has received to obtain such abilities and competencies. Lastly, relatedness means having a sense of belonging in the community. An individual who has it feels the stability in the community. Autonomy, competence, and relatedness are greatly influenced by the development and growth of individuals and the society. Autonomy, however, is most important for the maintenance and promotion of intrinsic motivation. The self-determination theory discusses the levels of intrinsic motivation based on autonomy.

Career decision-making autonomy pertains to autonomy in the career decision-making and preparation process. When an individual's career decision-making autonomy is high, he chooses a career based on his personal interests and on the degree of importance that he places on certain career options. It is based on the degree of autonomy of an individual. The selfdetermination theory cites operative definitions for intrinsic motivation, identified regulation, introjected regulation, and external regulation. It also measures these and sums them up. Career decision-making autonomy is calculated in the following way.

Career decision - making autonomy $=$

(intrinsic motivation + identified regulation)

-(introjected regulation + external regulation $)$

As for the career decision-making autonomy level of an individual, it is calculated as follows.

Career decision - making autonomy level of an individual $=$
$(2 \times$ intrinsic motivation + identified regulation $)$
$-($ introjected regulation $+2 \times$ external regulation $)$

Intrinsic motivation and autonomy can have positive results in the self-determination theory (Thompson \& Subich, 2007). The level of autonomy is high in the career decision made based on intrinsic motivation and identified regulation, and the level of autonomy is low in the career decision made based on introjected regulation and external regulation. If the basis of the career decision was personal satisfaction or pleasure, it shows the highest level of autonomy. When an act is important and is based on individual judgment (e.g. making a career decision), the level of autonomy involved in it is high. When an individual acts regardless of his own will due to external regulation or the social custom and culture, the level of autonomy involved in the act becomes lower. The self-determination theory also discusses the relation between the motivation and the career decision. When the intrinsic motivation is high, it is very useful for the career decision process. The impersonal orientation of amotivation is not related to the career decision-making act. The level of autonomy is influenced by the career indecision. When the career decision is high, the career indecision is low. The career decision efficacy acts as a parameter between self-determination and career indecision. The correlation between career decision-making autonomy and the career preparation act is insignificant. Conversely, intrinsic motivation, identified regulation, introjected regulation, and external regulation have significant correlations with the career preparation act. The level of autonomy has a significant correlation with career decision-making, but the level of autonomy of career decision-making has an insignificant correlation with the career preparation act. When the autonomy level of career decision-making is high, it is influenced by the career decision-making level and the career preparation act (Greenbank, 2011). The level of autonomy of career decision-making has 
a positive effect on the career preparation act. When the intrinsic motivation is high, the career preparation act is likely to be vibrantly executed.

Career decision-making self-efficacy is defined as the belief in one's capabilities as an individual. Self-efficacy is based on the social learning theory and refers to one's confidence in his individual abilities. The social learning theory emphasizes that self-efficacy involves an individual's act of thinking and imagining, and can be developed through the repetition of the given task. Self-efficacy is the effect of an individual act and is the major parameter between an act and an act change. The expected level of self-efficacy can be achieved through feedback from the external environment. Self-efficacy is influenced by the acts, thinking, emotions, environment, choices, etc. An individual performs a given task when he has confidence. Selfefficacy determines the effort level and the behavior persistence (Garcia, et al., 2015). The stronger the self-efficacy is, the higher the effort level and the behavior persistence. Selfefficacy is acquired through performance achievement, agent experience, social persuasion, and emotional perception. First, performance achievement is the decision factor of self-efficacy. In general, the degree of self-efficacy increases in the face of task success, and decreases in the face of task failure. As for agent experience, it is an efficient way of developing and enhancing self-efficacy. Here, an individual develops self-efficacy by observing other people performing the given task. Regarding social persuasion, it indicates that the degree of self-efficacy can be increased by the compliments and encouragement received from other people. Lastly, emotional perception signifies that the degree of self-efficacy is influenced by an individual's emotions. Positive emotions can increase self-efficacy while negative emotions can decrease it. In summary, the degree of self-efficacy is influenced by act selection, thinking, and emotions. When a person has a high degree of self-efficacy, he can perform the given task (Forsythe, et al., 2014). On the other hand, when a person has a low degree of self-efficacy, he cannot perform the given task. The degree of self-efficacy can change based on the level of difficulty of the given task, the situation, the variables involved, etc. Self-efficacy needs to be discussed further for career decision-making application.

The career preparation behavior is a specific behavior and not the general recognition of and attitude towards career decision-making. It signifies that the acts that will enable one to make the right career decision are performed. Predictability, expectedness, and preparedness are important for career preparation and forecasting (Stringer, et al., 2011). For preparedness, the expected negative result, strategy development, persistent efforts, etc. are needed. It has many suggestions for the career preparation behavior. Career decision-making and choice are very important in an individual's life. Persistent efforts are needed to obtain positive results and to be able to correctly forecast one's career. The career preparation behavior is related with career search self-efficacy, job search behavior, career-information-seeking behavior, etc. The career exploration behavior is similar to the career exploration behavior as they both involve importance recognition for information gathering. The career preparation behavior pertains to the implementation of commitment to the career decision that one made. Also, the career alternatives decrease through information gathering. The measurement tool for the career preparation behavior is the rational decision activity (Hirschi \& Herrmann, 2013). The career preparation behavior is the exploration behavior for the information gathering and preparation behavior for the career decision-making and employment. Also, it is the effort and the behavior required for making the right career decision and for career purpose achievement.

\section{The problem of rising unemployment among the youth}

Unemployment among the youth is one of the most serious social problems in South Korea, as well as in many other countries. However, the unemployment rate among the youth in South Korea is higher than those in other nations. Also, the unemployment rate among the 
youth in South Korea has increased faster than the unemployment rate among the youth in other nations. The unemployment rate among the youth in South Korea was 9.2\% in 2015. It is $0.2 \%$ higher than the unemployment rate of $9.0 \%$ in 2014 among the youth in South Korea. The unemployment rate among the youth has steadily increased since 2013. The unemployment rate among the youth in South Korea in 2015 is included among the OECD 5 countries, and is higher than the unemployment rate in 2014 among the youth. In particular, the unemployment rate for college graduates has increased every year. The rate of female graduates is higher than the rate of male graduates. The unemployment rate among college graduates has resulted in many social problems. At the personal level, social opportunities are rarely given to college graduates, despite their own human resource investment. It is a loss of opportunity in terms of social development through the utilization of knowledge and corresponding function. Furthermore, the unemployed faced serious setbacks. The competitiveness of the enterprise has weakened due to the unemployment of the manpower for new technology and new functions. Then, there is also the aging phenomenon affecting the enterprise. The unemployment rate among the youth lead to social unrest and marriage and childbirth evasion. Thus, it poses a serious social problem.

On a personal level, when job-seeking activities fail, it is highly probable that the person would go for a temporary job or could become a temporary employee. It occurs when there is a long-term economic recession and the unemployment rate is rising (Cooper, et al., 2016). Also, young people depend on their parents. Therefore, they tend to easily give up on jobseeking activities or they only seek a preferred occupation. It occurs when there is a deepening frustration as a result of long-term unemployment among the youth. Job search anxiety could occur. It is defined as the anxiety developing through the preparation for employment or the employment process itself. It means that there exists a threat (worry, emotional pressure, fear, and barrier to employment) leading to the failure in employment. Job-seeking stress refers to the mental and the physical anguish as a result of the repeated employment failure contributing to long-term unemployment (Minola et al., 2016). Job search anxiety can be positive, and serve as the developmental function for the motivation toward employment preparation. However, serious job search anxiety can be a negative influence on the employment preparation. It can lead to health problems, depression, social phobias, antisocial behavior, etc. College graduates become important human resources in reinforcing enterprise competitiveness. Among the enterprises in South Korea, new personnel is hired through open, competitive examination every year. They must demonstrate a remarkable ability to perform their duties in the enterprise. Long-term unemployment among college graduates can occur amid the unnatural organizational structure due to the difficulty in human resource staffing. In particular, the aging phenomenon has become a serious problem in the enterprise (Hui, et al., 2016). The enterprise is only focused on existing technology. Also, the enterprise's ability to come up with a solution reduces the risks of new problems. The enterprise must cope with the anti-business sentiment caused by the unemployment of the youth. Unemployment among the youth can lead to the dismantling of the community. The youth can become a group that is socially discontent because of repeated temporary employment and unemployment. The negative perception on the society can increase due to employment failure despite the efforts of young job seekers. In general, it acts as a cause for antisocial behavior and increasing deviance (Latorre, et al., 2016). Particularly, college graduates only look for a preferred occupation because their own human resource investment acts as sunk cost. College graduates highly prefer stable jobs. Therefore, the number of young people preparing for a civil service exam has increased. It can be considered as social loss (Biggane, et al., 2016). The youth can become a socially discontent group when a serious setback, such as failing a civil service exam, occurs (Gerolimetto \& Magrini, 2016). Also, it can be a risk toward family dissolution. Unemployment among the youth can lead to household poverty. Likewise, the family income decreases when the parent 
generation leaves the labor market through retirement. In particular, the delinquent borrower rate has grown due to youth unemployment. It has become a warning sign toward the risk of unemployment. Furthermore, unemployment among the youth can cause generation discord among insiders and outsiders, and it can be amplified due to lack of employment opportunities. The number of stable jobs (in major enterprises, public enterprises, etc.) has decreased continuously. The employment rate of college graduates for stable jobs has likewise decreased. Those in their 40s and 50s occupy existing stable jobs. Conflicts can occur between those in their 40s and 50s and the younger generation. Unemployment among the youth is also correlated with the emerging aging society. South Korea is moving toward becoming an aging society at a very rapid pace. The percentage of the working force in South Korea is expected to reach $55.1 \%$ in 2050 . It means that the economically active population would significantly decrease in the future. South Korea will be experiencing economic difficulty. New personnel employment and prospective investigation is described in Figure 1. It is a survey data (377 major enterprises in South Korea) of the Korea Employers' Federation.

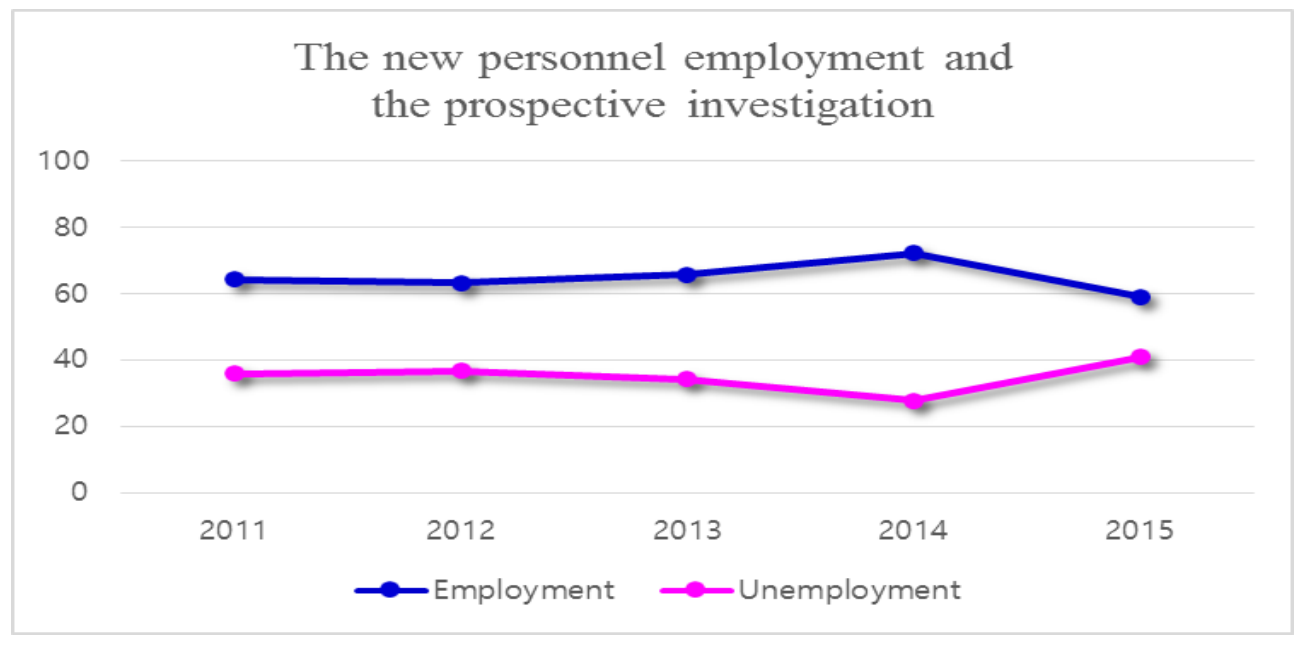

Figure 1. New personnel employment and prospective investigation

In this paper, we will focus on the analysis of the demand and the supply in the labor market in relation to the cause of unemployment among the youth. In the demand side of unemployment among the youth, enterprises supply jobs and require human resources. Unemployment among the youth occurs due to the low demand of the enterprise and demand structure changes in the labor force. The enterprise determines human resource demand through market demand. Particularly, capital demand is higher than human resource demand when the labor market is stiff. Therefore, unemployment among the youth occurs in the demand side. First, the recruitment method of the enterprise has changed. South Korea enterprises have hired human resources through large-scale, open, competitive examination. The enterprise is focused on employing college graduates with excellent potential every year. Recently, however, the social economic situation has been vague due to globalization and competition. Therefore, the recruitment method of the enterprise has changed from large-scale, open, competitive examination to small-scale, nonscheduled examination. Small-scale, nonscheduled examination tend to hire people with experience to reduce training cost. Small-scale, nonscheduled examination proves that college education is not significant. In South Korea, small-scale, nonscheduled examination has been expanded due to a short supply of human resources for new IT technology jobs. Second, the industrial structure change and the global human resource operation strategy are factors in the demand reduction of enterprises. The manufacturing industry in South Korea is focused on a higher value-added industry, such as the 
IT industry, whose employment inducement effect is low. The gross domestic product (GDP) growth contributions percentage of the information and communication industry have risen $21.9 \%$ (from 2013) in an annual report (2015) of the information and communication industry of the Ministry of Science, ICT, and Future Planning. However, employment rate was under $6 \%$ in all industries. Globalization and overseas investment have become limiting factors in domestic employment. The manufacturing industry has accounted for $30 \%$ in South Korea. The hollowing of the manufacturing industry and employment has occurred because the manufacturing industry of South Korea is poised to go overseas. Thus, large enterprises have reduced domesitc employment as they explore a new global strategy. In the supply side regarding unemployment among the youth, employment is related to the education system. In South Korea, the increase in the number of highly educated youth is the main cause. College graduates in South Korea have increased continuously. The number of college graduates in South Korea increased from 167,000 (1983) to 502,000 (2015). College graduates in South Korea was $65 \%$ of the population (25-34-year-olds, 2013). However, the OECD average was $40 \%$. The college entrance rate in South Korea was over $70.9 \%$ (2014) due to university liberalization. It includes unemployment among the youth and the insolvency of local universities. The population (25-34-year-olds) rate of college graduates in OECD (Education at a Glance, 2013) is described in Table 1. In South Korea, 500,000 young people enter the labor market each year. It has depressed the labor market. Second, problems in the quality of education has affected the growing number of college graduates. The problem in the quality of university education is the cause for the demand reduction in the enterprise and in the increase in reeducation cost. Third, college graduates only prefer stable and decent jobs. Also, they prefer joining a large enterprise, a public corporation, a financial institution, etc., and enter the large-scale, open, competitive examination. However, they avoid small enterprises, which suffer from a labor shortage problem. College graduates only look for preferred jobs because their own human resource investment acts as sunk cost. Thus, it requires a rational solution.

Table 1. The population (25-34-year-olds) rate of college graduates in OECD (Education at a Glance, 2013)

\begin{tabular}{cccccc}
\hline United States & United Kingdom & Canada & Japan & South Korea & OECD average \\
\hline $43 \%$ & $48 \%$ & $57 \%$ & $60 \%$ & $65 \%$ & $40 \%$ \\
\hline
\end{tabular}

\section{Methodology}

In this paper, we analyzed the employment rate of university majors to come up with an effective solution to avert the rise in unemployment among the youth. The employment rate calculation on the data for analysis is based on the 'Higher Education in Korea' of the Minister of Education of South Korea. Below is the detailed formula.

$$
\text { Employment rate }(\%)=100 \times \frac{B}{A-(C+D+E+F+G)}
$$

Employee $(B)=$ National health insurance subscriber

Pure university graduate $=$ University graduate $(A)-\{$ Graduate school advancement $(C)$ + Joining army $(D)+$ Employment impossibility $(E)+$ International student $(F)$ + National health insurance subscriber exception $(G)\}$ 
Also, the university graduate scale can be presumed for jobs. Is the weight of the employment survey. Below is the detailed formula.

$$
\sum_{j=1}^{n} w_{i}=O C C_{s j}
$$

The demand for the university graduate scale can be estimated through a sum for the entire job. Below is the detailed formula.

$$
\sum_{j=1}^{n} O C C_{s j}
$$

In this paper, the employment statistics result (2014) in the database for health insurance and the national tax of college graduates is utilized. It presented the employment statistics result from the Korean Educational Development Institute (KEDI) of the Ministry of Education of South Korea. The objects of analysis were college graduates.

This paper analyzed the effect of job search anxiety and job decision in preparation for employment so that a policy could be proposed to improve employment rate. Also, the mediator effect was used to investigate self-efficacy in relation to the job decision. The research model is described in Figure 2.

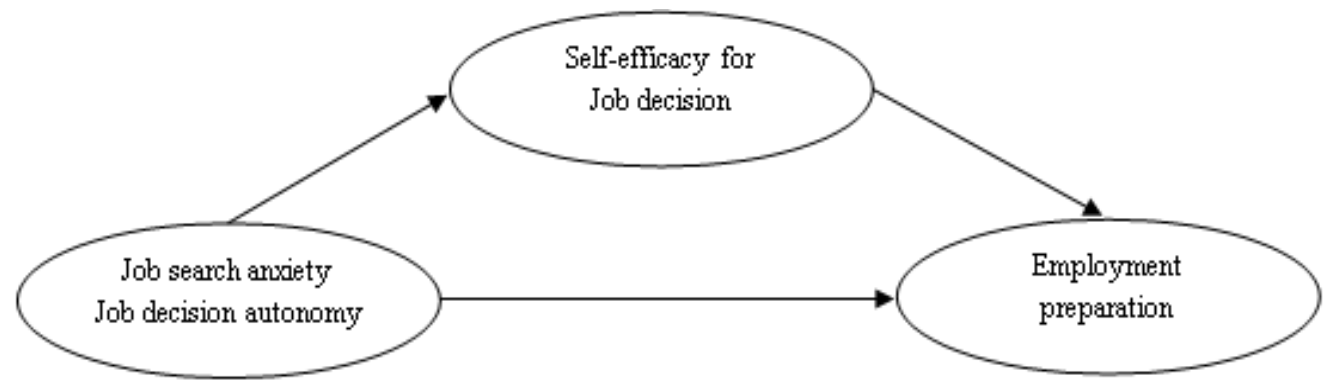

Figure 2. The research model

We surveyed 100 university students from Seoul to analyze such effect. The population statistics variables used in analyzing the effect is described in Table 2. We analyzed the factors in the descriptive statistics calculation. The Cronbach's a coefficient is calculated for the confidence verification of the measurement. A correlation analysis and a regression analysis are then performed to analyze the effect of job search anxiety and job decision in the preparation for employment.

Table 2. The population statistics variables for the effect analysis $(\mathrm{N}=100)$

\begin{tabular}{ccc}
\hline Classification & Frequency & Rate (\%) \\
\hline Male & 60 & 60 \\
Female & 40 & 40 \\
\hline Third year & 38 & 38 \\
Fourth year & 62 & 62 \\
\hline Humanities and social science & 32 & 32 \\
Engineering and natural science & 41 & 41 \\
Management and Economics & 16 & 16 \\
Physical Education and Art & 11 & 11 \\
\hline
\end{tabular}


In this paper, the hypothesis of the job search activity and the preparation for employment on job search anxiety is follows as.

$H_{0}=J o b$ search anxiety is influenced in job search activity,

employment preparation, and job decision activity

$H_{1}=J o b$ search anxiety is not influenced in job search activity,

employment preparation, and job decision activity

In this paper, the hypothesis of the job decision activity for the lower factors of the job search anxiety is follows as.

$H_{0}=J o b$ search anxiety situation, situation leading to job search anxiety, and cause of job search anxiety is influenced in job decision activity

$H_{1}=$ Job search anxiety situation, situation leading to job search anxiety, and cause of job search anxiety is not influenced in job decision activity

In this paper, the hypothesis of the job decision activity for the job decision autonomy for the lower factors of the job search anxiety is follows as.

$H_{0}=J o b$ decision autonomy is influenced in job search activity, employment preparation, and job decision activity

$H_{1}=J o b$ decision autonomy is not influenced in job search activity, employment preparation, and job decision activity

In this paper, the hypothesis of the job decision activity for the lower factors of the job decision autonomy is follows as.

$H_{0}=$ External control, imposed control, and identified control, and intrinsic motivation is influenced in job decision activity

$H_{1}=$ External control, imposed control, and identified control, and intrinsic motivation is not influenced in job decision activity

\section{Results}

The employment statistics result (2014) from the database of the health insurance and the national tax of college graduates is described in Table 3. The employment rate of college graduates was $64.5 \%$. It fell $0.3 \%$ compared to the data in 2013. The employment rate on dental medicine was $90.0 \%$, Korean medicine was $89.6 \%$, and general medicine was $88.3 \%$. The employment rate among males was $67.2 \%$, while the employment rate among females was $62.0 \%$. The employment rate of males is $5.2 \%$ higher than females. However, the employment rate of females steadily increased. 
Table 3. The employment statistics result (2014) from the database for the health insurance and the national tax of college graduates

\begin{tabular}{|c|c|c|c|c|c|c|c|c|c|c|c|}
\hline \multirow[b]{2}{*}{$\begin{array}{l}\text { Colleg } \\
\text { e } \\
\text { gradua } \\
\text { tes }\end{array}$} & \multirow[b]{2}{*}{$\begin{array}{c}\text { Employ } \\
\text { ment } \\
\text { candidat } \\
\mathrm{e}\end{array}$} & \multicolumn{7}{|c|}{ Employment } & \multirow[b]{2}{*}{$\begin{array}{c}2014 \\
\text { Employ } \\
\text { ment } \\
\text { rate }(\mathrm{A})\end{array}$} & \multirow[b]{2}{*}{$\begin{array}{c}2013 \\
\text { Employ } \\
\text { ment } \\
\text { rate }(\mathrm{B})\end{array}$} & \multirow[b]{2}{*}{$\begin{array}{c}\text { Employ } \\
\text { ment } \\
\text { rate } \\
\text { variation } \\
\text { (A-B) }\end{array}$} \\
\hline & & $\begin{array}{c}\text { Tota } \\
1\end{array}$ & $\begin{array}{l}\text { Health } \\
\text { insura } \\
\text { nce } \\
\text { applic } \\
\text { ant }\end{array}$ & $\begin{array}{c}\text { Oversea } \\
\text { s } \\
\text { employ } \\
\text { ment }\end{array}$ & $\begin{array}{l}\text { Agricult } \\
\text { ural and } \\
\text { fisheries }\end{array}$ & $\begin{array}{c}\text { Founda } \\
\text { tion }\end{array}$ & $\begin{array}{c}\text { Freelan } \\
\text { cer }\end{array}$ & $\begin{array}{l}\text { Individ } \\
\text { ual } \\
\text { creativ } \\
\mathrm{e} \\
\text { activit } \\
\mathrm{y} \\
\end{array}$ & & & \\
\hline 301,606 & 261,068 & $\begin{array}{c}168,5 \\
10 \\
\end{array}$ & 154,507 & 601 & 135 & 1,815 & 10,323 & 1,129 & $64.5 \%$ & $64.8 \%$ & $-0.3 \%$ \\
\hline
\end{tabular}

Table 4. The employment retention rate of college graduates (2014)

\begin{tabular}{cccc}
\hline 3 months & 6 months & 9 months & 12 months \\
\hline $90.0 \%$ & $84.6 \%$ & $78.0 \%$ & $74.4 \%$ \\
\hline
\end{tabular}

Table 5. The overseas employment rate (2014)

\begin{tabular}{ccccc}
\hline United States & Japan & Singapore & Vietnam & Indonesia \\
\hline $25.6 \%$ & $18.5 \%$ & $11.0 \%$ & $5.8 \%$ & $5.8 \%$ \\
\hline
\end{tabular}

Table 6. The employment rate of 7 majors (2014)

\begin{tabular}{|c|c|c|c|c|c|c|c|c|c|c|c|}
\hline \multirow[b]{2}{*}{$\begin{array}{l}\text { Classific } \\
\text { ation }\end{array}$} & \multirow[b]{2}{*}{$\begin{array}{l}\text { Employ } \\
\text { ment } \\
\text { rate }(\%)\end{array}$} & \multirow{2}{*}{$\begin{array}{l}\text { Graduate } \\
\text { school } \\
\text { advance } \\
\text { ment rate } \\
(\%)\end{array}$} & \multirow[b]{2}{*}{$\begin{array}{l}\text { Colleg } \\
\text { e } \\
\text { gradua } \\
\text { tes }\end{array}$} & \multicolumn{8}{|c|}{ College graduates' Circumstances } \\
\hline & & & & $\begin{array}{l}\text { Employ } \\
\text { ment }\end{array}$ & $\begin{array}{c}\text { Graduate } \\
\text { school } \\
\text { advance } \\
\text { ment }\end{array}$ & $\begin{array}{l}\text { Milita } \\
\text { ry }\end{array}$ & $\begin{array}{c}\text { Joble } \\
\text { ss }\end{array}$ & $\begin{array}{c}\text { Except } \\
\text { ion }\end{array}$ & $\begin{array}{l}\text { Othe } \\
\text { rs }\end{array}$ & $\begin{array}{l}\text { Unkno } \\
\text { wn }\end{array}$ & $\begin{array}{c}\text { Internati } \\
\text { onal } \\
\text { students }\end{array}$ \\
\hline Total & 64.5 & 8.5 & $\begin{array}{c}301,60 \\
6\end{array}$ & 168,510 & 25,507 & 1,773 & 110 & 3,431 & $\begin{array}{c}89,7 \\
04\end{array}$ & 2,854 & 9,717 \\
\hline $\begin{array}{l}\text { Humaniti } \\
\text { es }\end{array}$ & 57.5 & 8.5 & 38,718 & 18,375 & 3,308 & 192 & 22 & 1,768 & $\begin{array}{c}13,0 \\
27\end{array}$ & 553 & 1,473 \\
\hline $\begin{array}{c}\text { Social } \\
\text { science }\end{array}$ & 62.3 & 3.2 & 90,239 & 50,339 & 2,896 & 319 & 29 & 630 & $\begin{array}{c}29,4 \\
62\end{array}$ & 1,031 & 5,533 \\
\hline $\begin{array}{c}\text { Educatio } \\
\mathrm{n}\end{array}$ & 52.9 & 4.8 & 15,360 & 7,386 & 744 & 108 & 0 & 417 & $\begin{array}{c}6,48 \\
6\end{array}$ & 89 & 130 \\
\hline $\begin{array}{l}\text { Engineeri } \\
\text { ng }\end{array}$ & 73.3 & 12.3 & 69,417 & 43,506 & 8,508 & 307 & 22 & 151 & $\begin{array}{c}15,3 \\
40\end{array}$ & 500 & 1,083 \\
\hline $\begin{array}{l}\text { Natural } \\
\text { science }\end{array}$ & 61.9 & 19.8 & 36,529 & 17,563 & 7,220 & 160 & 13 & 159 & $\begin{array}{c}10,4 \\
88\end{array}$ & 324 & 602 \\
\hline Medicine & 81.4 & 2.9 & 16,992 & 13,263 & 497 & 77 & 9 & 65 & $\begin{array}{c}2,95 \\
9\end{array}$ & 64 & 58 \\
\hline $\begin{array}{l}\text { Physical } \\
\text { Educatio } \\
\mathrm{n} \text { and Art }\end{array}$ & 59.6 & 6.8 & 34,351 & 18,078 & 2,334 & 610 & 15 & 241 & $\begin{array}{c}11,9 \\
42\end{array}$ & 293 & 838 \\
\hline
\end{tabular}


Table 7. The top ranking majors and employment rate (2014)

\begin{tabular}{cccc}
\hline Major & College graduates & Employment rate (\%) & $\begin{array}{c}\text { Graduate school } \\
\text { advancement rate }(\%)\end{array}$ \\
\hline Dental medicine & 706 & 88.6 & 1.6 \\
Korean medicine & 263 & 84.8 & 2.3 \\
Medicine & 550 & 83.4 & 4.7 \\
Nursing & 6,659 & 82.2 & 0.5 \\
Rehabilitation & 1,899 & 81.1 & 2.4 \\
Elementary education & 231 & 80.4 & 2.2 \\
Electrical engineering & 212 & 80.1 & 11.8 \\
Early childhood & 2,630 & 77.1 & 1.1 \\
education & & & \\
\hline
\end{tabular}

Table 8 . The regression analysis on employment rate

\begin{tabular}{|c|c|c|c|}
\hline \multicolumn{2}{|c|}{ Classification } & 2013 & 2014 \\
\hline \multicolumn{2}{|c|}{ Constant term } & $0.56^{* * *}$ & $0.59 * * *$ \\
\hline \multirow{6}{*}{$\begin{array}{c}\text { Major }(\text { Social science }= \\
0)\end{array}$} & Humanities & $-0.04 * * *$ & $-0.05^{* * *}$ \\
\hline & Education & $-0.06^{* * *}$ & $-0.03 * * *$ \\
\hline & Engineering & $0.10^{* * *}$ & $0.11^{* * *}$ \\
\hline & Natural science & -0.02 & $-0.01 *$ \\
\hline & Medicine & $0.21 * * *$ & $0.20 * * *$ \\
\hline & $\begin{array}{l}\text { Physical Education and } \\
\text { Art }\end{array}$ & $-0.12 * * *$ & $-0.08 * * *$ \\
\hline \multicolumn{2}{|c|}{ Female rate } & $-0.04 * * *$ & $-0.05^{* * *}$ \\
\hline \multicolumn{2}{|c|}{ Region (capital region universities $=0$ ) } & 0.00 & 0.00 \\
\hline \multicolumn{2}{|c|}{ F Value } & $234.61 * * *$ & $191.03 * * *$ \\
\hline \multicolumn{2}{|c|}{ Adj R-Sq } & 0.23 & 0.29 \\
\hline \multicolumn{2}{|c|}{ Index number of observation } & 5.031 & 5.067 \\
\hline
\end{tabular}

$* \mathrm{p}<0.1, * * \mathrm{p}<0.05, * * * \mathrm{p}<0.01$

The survey on employment rate (2014) contained several meaningful facts. First, the disparity on employment rate between capital region universities and noncapital region universities steadily decreased since 2012 due to the employment rate increase in noncapital region universities. There is a disparity on employment rate between capital region universities and noncapital region universities from $2012(1.4 \%) \rightarrow 2013(1.3 \%) \rightarrow 2014(0.8 \%)$. Second, the employment rate among females is consistently growing though it is comparatively lower than the males. The disparity on employment rate between females and males has steadily decreased. The disparity on employment rate between females and males is as follows: 2011 $(6.2 \%) \rightarrow 2012(4.9 \%) \rightarrow 2013(4.8 \%) \rightarrow 2014(3.8 \%)$. Third, the employment retention rate of college graduates $(2014)$ ranged from 3 months $(90.0 \%) \rightarrow 6$ months $(84.6 \%) \rightarrow 9$ months $(78.0 \%) \rightarrow 12$ months $(74.4 \%)$. The employment retention rate of college graduates $(2014)$ is described in Table 4. Overseas employment included 601 people. The overseas employment rate (2014) is described in Table 5. The employment rate under 7 majors (humanities, social science, education, engineering, natural science, medicine, and physical education and art) were $81.4 \%$ for medicine, $73.3 \%$ for engineering, and $62.3 \%$ for social science. The graduate school advancement rate covered natural science at $19.8 \%$, engineering at $12.3 \%$, and humanities at 
8.5\%. The employment rate under 7 majors (2014) is described in Table 6. Among the majors with high employment rates (2014) were dental medicine at $90.0 \%$, Korean medicine at $89.6 \%$, and general medicine at $88.3 \%$. The top ranking majors with high employment rates (2014) are described in Table 7. The regression analysis on the employment rate is described in Table 8. The results showed that the major has a significant effect on employment. The employment rate of medicine and engineering majors was high. On the other hand, the employment rate of physical education and art majors, humanities majors, and education majors were low. Natural science has a lower significance level than social science.

The mean and the standard deviation for the measurement variation is described in Table 9. The result showed that job search anxiety and the employment preparation of fourthyear students are larger than those of third-year students. The Pearson correlation coefficient is analyzed for the correlation analysis of the verified items. The correlation of measured variables is described in Table 10. The result of the analysis showed that job search anxiety had a negative correlation $(\mathrm{r}=-0.12, \mathrm{p}<0.05)$ in the job decision activity. Job decision autonomy had a positive correlation $(r=0.06, p>0.05)$ in the job decision activity. However, it was not statistically significant. The identified control $(r=0.16, p<0.05)$ and the intrinsic motivation $(\mathrm{r}=0.21, \mathrm{p}<0.01)$ had a positive correlation in the job decision activity involving lower factors of the job decision autonomy. The self-efficacy in the job decision had a negative correlation $(\mathrm{r}$ $=-0.31, \mathrm{p}<0.01)$. Also, it had a positive correlation in the job decision autonomy $(\mathrm{r}=0.28, \mathrm{p}$ $<0.01)$, and in the job decision activity $(\mathrm{r}=0.41, \mathrm{p}<0.01)$. The simple regression used in analyzing the effect of job search activity and employment preparation on job search anxiety is described in Table 11. Job search anxiety had a negative correlation $(\beta=-0.137, p<0.05)$ on employment preparation. Likewise, job search anxiety had a negative correlation $(\beta=-0.079$, $\mathrm{p}>0.05)$ on the job search activity. However, it was not statistically significant. Also, it had a negative correlation $(\beta=-0.143, p<0.05)$ on employment preparation. The simple regression used in analyzing the effect of the job decision activity on lower factors (the job search anxiety situation, the situation leading to job search anxiety, and the cause of job search anxiety) of the job search anxiety is described in Table 12. The job search anxiety situation had a positive correlation $(\beta=0.014, \mathrm{p}>0.05)$ on the job decision activity. However, it was not statistically significant. The situation leading to job search anxiety $(\beta=-0.169, \mathrm{p}<0.01)$ and the cause of job search anxiety $(\beta=-0.201, \mathrm{p}<0.01)$ had a negative correlation on the job decision activity.

Table 9. The mean and the standard deviation for the measurement variation

\begin{tabular}{cccc}
\hline \multirow{2}{*}{ Measurement variation } & Third year $(\mathrm{N}=38)$ & Fourth year $(\mathrm{N}=62)$ & Total $(\mathrm{N}=100)$ \\
\cline { 2 - 4 } & $\mathrm{M}(\mathrm{SD})$ & $\mathrm{M}(\mathrm{SD})$ & $\mathrm{M}(\mathrm{SD})$ \\
\hline Job search anxiety & $3.01(0.59)$ & $3.23(0.81)$ & $3.12(0.67)$ \\
Job decision autonomy & $2.30(2.87)$ & $2.01(2.60)$ & $2.17(2.79)$ \\
Employment preparation & $2.83(0.61)$ & $3.16(0.69)$ & $3.04(0.68)$ \\
Self-efficacy for job & $3.17(0.45)$ & $3.20(0.51)$ & $3.18(0.47)$ \\
decision & & & \\
\hline
\end{tabular}


Table 10. The correlation of measuring variables $(\mathrm{N}=100)$

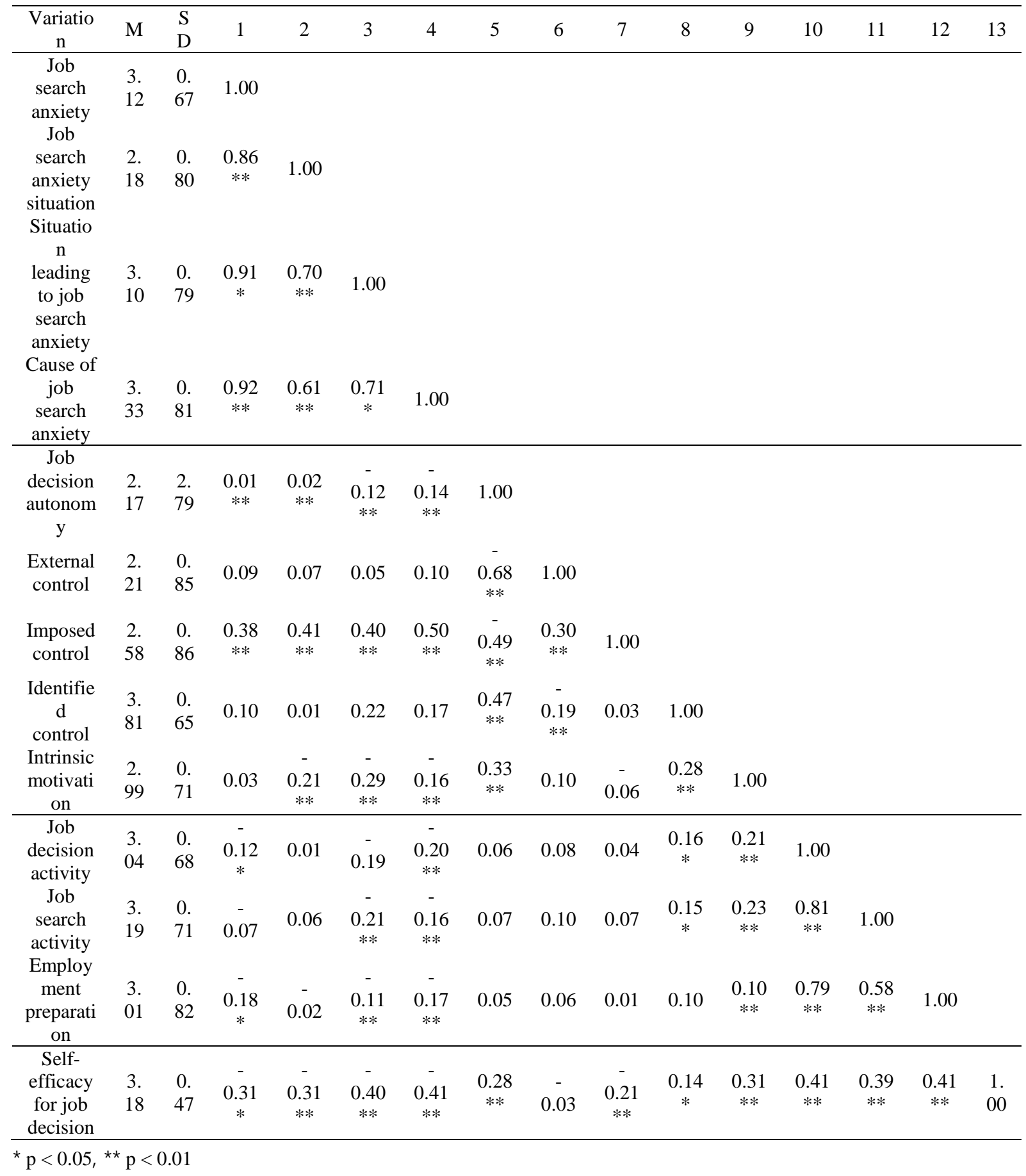

Table 11. The simple regression on the analysis of the effect on the job search activity and the preparation for employment on job search anxiety $(\mathrm{N}=100)$

\begin{tabular}{cccccc}
\hline $\begin{array}{c}\text { Independent } \\
\text { variable }\end{array}$ & Dependent variable & $\beta$ & $\mathrm{t}$ & $\mathrm{R}^{2}$ & $\mathrm{~F}$ \\
\hline \multirow{2}{*}{$\begin{array}{c}\text { Job search } \\
\text { anxiety }\end{array}$} & $\begin{array}{c}\text { Employment } \\
\text { preparation }\end{array}$ & -0.079 & -1.21 & 0.007 & 1.480 \\
& Job decision activity & $-0.137^{*}$ & -2.38 & 0.021 & $5.041^{*}$ \\
$* \mathrm{p}<0.05$ & & & & & \\
\hline
\end{tabular}


Table 12. The simple regression on the analysis of the effect on the job decision activity for the lower factors of the job search anxiety $(\mathrm{N}=100)$

\begin{tabular}{cccccc}
\hline Independent variable & $\begin{array}{c}\text { Dependent } \\
\text { variable }\end{array}$ & $\beta$ & $\mathrm{t}$ & $\mathrm{R}^{2}$ & $\mathrm{~F}$ \\
\hline $\begin{array}{c}\text { Job search anxiety } \\
\text { situation }\end{array}$ & & 0.014 & 0.279 & 0.005 & 0.480 \\
$\begin{array}{c}\text { Situation leading to job } \\
\text { search anxiety } \\
\begin{array}{c}\text { Cause of job search } \\
\text { anxiety }\end{array}\end{array}$ & $\begin{array}{c}\text { Job decision } \\
\text { activity }\end{array}$ & $-0.169^{*}$ & -2.123 & 0.011 & $5.931^{*}$ \\
\hline
\end{tabular}

$* \mathrm{p}<0.05,{ }^{* *} \mathrm{p}<0.01$

Table 13. The simple regression on the analysis of the effect on job decision autonomy for the lower factors of the job search anxiety $(\mathrm{N}=100)$

\begin{tabular}{cccccc}
\hline $\begin{array}{c}\text { Independent } \\
\text { variable }\end{array}$ & Dependent variable & $\beta$ & $\mathrm{t}$ & $\mathrm{R}^{2}$ & $\mathrm{~F}$ \\
\hline Job decision & Job search activity & 0.081 & 1.114 & 0.006 & 1.210 \\
autonomy & Employment preparation & 0.041 & 0.504 & 0.001 & 0.871 \\
$* \mathrm{p}<0.05$ & Job decision activity & 0.070 & 1.003 & 0.005 & 1.041 \\
\hline
\end{tabular}

Table 14. The simple regression on the analysis of the effect on the job decision activity for the lower factors of the job decision autonomy $(\mathrm{N}=100)$

\begin{tabular}{cccccc}
\hline $\begin{array}{c}\text { Independent } \\
\text { variable }\end{array}$ & Dependent variable & $\beta$ & $\mathrm{t}$ & $\mathrm{R}^{2}$ & $\mathrm{~F}$ \\
\hline External control & & 0.080 & 1.206 & 0.003 & 1.801 \\
Imposed control & Job decision activity & 0.670 & 0.845 & 0.008 & 0.701 \\
Identified control & $0.161^{*}$ & 2.106 & 0.017 & $4.130^{*}$ \\
Intrinsic motivation & & $0.213^{* *}$ & 3.191 & 0.043 & $9.034^{* *}$ \\
\hline
\end{tabular}

$* \mathrm{p}<0.05,{ }^{* *} \mathrm{p}<0.01$

The simple regression used in analyzing the effect of the job decision autonomy on the lower factors (the job decision activity and the preparation for employment) of the job search anxiety is described in Table 13. The job decision autonomy had a positive correlation $(\beta=$ $0.070, p>0.05)$ on the job decision activity. However, it was not statistically significant. Also, the job decision activity $(\beta=0.081, p>0.05)$ and the preparation for employment $(\beta=0.041$, $\mathrm{p}>0.05)$ were not statistically significant. In the result of the correlation analysis, the identified control and the intrinsic motivation had a correlation on the job decision activity. The simple regression used in analyzing the effect of the job decision activity on the lower factors of the job decision autonomy is described in Table 14 . The identified control $(\beta=0.161, \mathrm{p}<0.05)$ and the intrinsic motivation $(\beta=0.213, \mathrm{p}<0.01)$ had a positive correlation on the job decision activity. The result of the analysis showed that job search anxiety had a negative correlation on the job decision activity. Job search anxiety had a significant effect on the preparation for employment. However, it did not have a significant effect on the job search activity. The situation leading to job search anxiety and the cause of job search anxiety had a negative correlation on the job search activity. Also, job search anxiety did not have a significant effect on the job search activity. It was not statistically significant. The job decision autonomy did not have a significant effect on the job search activity. The identified control and the intrinsic motivation had a positive correlation on the job search activity. The higher the level of job search anxiety, the lower the level of the job search activity. Job search anxiety did not have a significant effect on the job search activity. The situation leading to job search anxiety and the 
cause of job search anxiety had a negative correlation on the job search activity. Consequently, job decision autonomy did not have a significant effect on the job search activity.

\section{Discussion}

The South Korean government is working on countermeasures that will improve the employment rate. However, it did not appear to come out with distinguished accomplishments in terms of government policy. The government's countermeasures to improve the employment rate and to deal with the rising unemployment among the youth can be summed up in three policies: First, job creation through economic growth. Job creation depends on economic activation. Also, the object of job creation is to make available promising jobs to young people as the economy remains robust. Second, the employment policy must focus on the public sector. The public sector can reflect the political will to support the economic sector. The public sector must function as the social safety network in times of employment crises. Its function as a social safety network means that jobs are provided or employment opportunities are offered to solve the crisis. Third, the policy must focus on the job supply. Employment can be expanded through deregulated enterprises. Job creation through economic growth, an employment policy that is focused on the public sector, and a policy focused on job supply, however, can be in conflict with the current economic paradigm. Also, these policies must be critically examined because they can be distorted, based on market function. First, job creation through economic growth is theoretically appropriate. However, it is limited in its function as a realistic alternative. South Korea has already passed the period of high economic growth. The rise in the number of the jobless has been a common phenomenon in South Korea. The South Korean government is exerting an effort to create good jobs with an economic growth of 7 percent or higher. Economic growth has been very limited due to the 2008 global financial crisis, the volatility of oil prices, etc. Still, consistent economic growth is needed to improve the employment rate. Realistically, continuous economic growth is difficult to attain. A solution must be suggested to expand the availability of good jobs despite low economic growth. Second, an employment policy that is focused on the public sector can be restrictive. Recently, an employment policy that is focused on the public sector could not be implemented properly due to the difficult economic situation. The government is focused on the reformation of the public sector through efficiency. The public sector must be based on rationality and fairness, and not on market principle. Therefore, the application of the market principle is not practical. The solutions of the public sector to help improve the employment rate include intern system expansion, pay adjustments for new employees, the salary peak system, etc. The public sector performs a social function for employment retention and job creation. A short-term employment policy is invalid because employment is not continuous. Also, it lacks legitimacy. Third, a policy focused on job supply concerns the employment opportunity expansion of the enterprise. Large enterprises in South Korea present a plan for a large number of employees every year. The artificial job supply is risky in the long term because of the increased responsibility of the enterprise activity. In particular, the artificial job supply poses a high risk because of continuously changing manpower utilization and enterprise management methods. The enterprise is focused on the flexible management of the manpower with an uncertain provision for globalization. For the enterprise, the irregular employment strategy is preferred over the existing regular employment strategy. Also, the employment scale is decreased. The enterprise decreases the number of their employees, and increases the rate of global outsourcing amid a cyclical economic depression and uncertain international environment. There could be a mismatch on the demand and the supply for manpower. Practically, the number of college graduates has significantly increased. However, the number of people with professional knowledge and function has been few. Consequently, enterprises have found it difficult to create jobs due to industrial structure 
changes. Recently, the industry in South Korea is focused on a higher value-added industry. Still, it has a very low employment inducement effect compared to the manufacturing industry. The manufacturing industry has captured $30 \%$ of the total employment in South Korea (2015). The correlation between the manufacturing industry and employment has become hollow because the manufacturing industry has gone abroad. A large number of employment through enterprises has a structural limitation. Enterprises must deal with the distortion of the internal resource distribution and insolvency in the long term.

\section{Conclusion}

Rising unemployment among the youth occurs as an individual problem, and is a result of the distortion of the labor market for enterprises. The generation discord among employees and the diffusion of the unstable class can disband a community. Therefore, an efficient policy must be implemented as a possible solution. First, a new perspective establishment is needed amid changing times and the growth in the number of the jobless. Recently, the rising unemployment among the youth has faced different characteristics against the manufacturing industry of the past. In particular, the economic growth for a higher value-added industry cannot offset large-scale employment due to low employment inducement coefficient. Therefore, economic growth is not always equated with employment. The employment-friendly, valueadded industry can contribute to a rise in value and employment creation. The new generation must be allowed to grow through the establishment of a higher value-added service industry (medicine, law, etc.). Second, small and medium enterprises must be converted as attractive job opportunities. College graduates prefer good and stable jobs. Small and medium enterprises lack human resources despite the rising unemployment of young people. College graduates do not prefer small and medium enterprises due to the lack of potential for career development, a lower social recognition, and the growth limitation of small and medium enterprises more than the low pay and the welfare.

The subcontract relationship between small and medium enterprises and large enterprises must be improved to solve this problem. Small and medium enterprises are almost sub-contracted firms of large enterprises. Therefore, college graduates do not prefer small and medium enterprises. Also, small and medium enterprises find it difficult to support the training and the career development of its staff due to poor financial conditions. Small and medium enterprises require government support for the training and the career development of its staff. The expansion of social recognition is necessary to uphold the importance of the roles of small and medium enterprises. Third, a short-term solution is consistently required in times of crisis. Recently, the intern system and employment training have been expanded. In general, a shortterm solution is very critical. An efficient solution is meeting social demand. Therefore, a shortterm solution must be consistent. The expansion of the intern system is needed for a higher value-added, new service industry, such as knowledge service, culture contents, etc. Fourth, an innovative policy is needed for job creation. Job creation provides an opportunity for selfemployment. It means that the growth power of future industries has been explored. Also, it requires heavy investment. Job creation can be vitalized in the society at large. This new generation has new ideas and a challenging consciousness. However, active investment is needed to commercialize a new idea and to challenge the consciousness. Likewise, professional organizations must be promoted to spur job creation.

The government must focus on information provision, fund support toward job creation, etc. The professional organization must focus on creation enterprise, idea exploration, job creation strategy, etc. Also, a partnership between the government and the professional organization must be established. Fifth, the social responsibility model is needed with the enterprise as the leading entity. The employment policy of the government can hardly be free 
from its political nature. Moreover, it has limited sustainability. The employment policy must be implemented through the initiative of the enterprise. The government must induce investment from the enterprise and perform various functions. The support policy for the competitiveness enhancement of the enterprise must be prioritized over temporary economic support. Upfront investments for the enterprise create a social responsibility foundation. The enterprise can employ staff based on market demand. Investment is necessary in the employment-friendly, value-added industry. Furthermore, it is a new effort that the enterprise can run parallel with social responsibility and its profit-oriented purpose.

\section{References}

Biggane, J. E., Allen, D. G., \& Albert, L. S. (2016). The role of positive illusions in employment relationships. Human Resource Management Review, 26(3), 270-281.

Cooper, S., Skelton, A. C., Owen, A., Densley-Tingley, D., \& Allwood, J. M. (2016). A multimethod approach for analysing the potential employment impacts of material efficiency. Resources conservation recycling, 109, 54-66.

Falco, P. \& Haywood, L. (2016). Entrepreneurship versus joblessness: Explaining the rise in self-employment. Journal of development economics, 118, 245-265.

Forsythe, L. P., Alfano, C. M., Kent, E. E., Weaver, K. E., Bellizzi, K., Arora, N., Aziz, N., Keel, G., \& Rowland, J. H. (2014). Social support, self-efficacy for decision-making, and follow-up care use in long-term cancer survivors. Psychooncology, 23(7), 788-796.

Garcia, P. R., Restubog, S. L., Bordia, P., Bordia, S., \& Roxas, R. E. (2015). Career optimism: The roles of contextual support and career decision-making self-efficacy, Journal of Vocational Behavior, 88, 10-18.

Gerolimetto, M. \& Magrini, S. (2016). A spatial analysis of employment multipliers in the US, Letters in Spatial and Resource Sciences, 9(3), 277-285.

Greenbank, P. (2011). Improving the process of career decision making: an action research approach, Education and Training, 53(4), 252-266.

Hirschi, A. \& Herrmann, A. (2013). Calling and career preparation: Investigating developmental patterns and temporal precedence, Journal of vocational behavior, 83(1), 51-60.

Hui, W., Haipeng, Z., \& Jintao, X. (2016). Analysis on the effects of key state-owned forestry reform on employment, Scientia Silvae Sinicae, 52(4), 83-90.

Latorre, F., Guest, D., Ramos, J., \& Gracia, F. J. (2016). High commitment HR practices, the employment relationship and job performance: A test of a mediation model, European Management Journal, 34(4), 328-337.

Launov, A. \& Wälde, K. (2016). The employment effect of reforming a public employment agency, European economic review, 84, 140-164.

Ministry of Economy and Finance of South Korea. (2017). National index system, http://www.index.go.kr.

Minola, T., Criaco, G., \& Obschonka, M. (2016). Age, culture, and self-employment motivation, Small Business Economics, 46(2), 187-213.

Reisel, W. D., Probst, T. M., Chia, S. L., Maloles, C. M., \& Konig, C. J. (2010). The Effects of Job Insecurity on Job Satisfaction, Organizational Citizenship Behavior, Deviant Behavior, and Negative Emotions of Employees, International Studies of Management \& Organization, 40(1), 74-91.

Schreurs, B., van Emmerik, H., Notelaers, G., \& De Witte, H. (2010). Job insecurity and employee health: The buffering potential of job control and job self-efficacy, Work and Stress, 24(1), 56-72. 
Stringer, K., Kerpelman, J., \& Skorikov, V. (2011). Career preparation: A longitudinal, processoriented examination, Journal of vocational behavior, 79(1), 158-169.

Teixeira, P. (2012). Applying self-determination theory and motivational interviewing to weight control: Linking values, goals and behaviour, Journal of Science and Medicine in Sport, 15(1), 4-10.

Thompson, M. N. \& Subich, L. M. (2007). The relation of social status to the career decisionmaking process, Journal of vocational behavior, 69(2), 289-301.

Wininger, S. (2007). Self-Determination Theory and Exercise Behavior: An Examination of the Psychometric Properties of the Exercise Motivation Scale, Journal of applied sport psychology, 19(4), 471-486. 